\title{
Effects of Antioxidant Micronutrients against CVD Risk in Type 2 Diabetes Mellitus: A Systematic Review
}

\section{Odeafo Asamoah-Boakye*, Charles Apprey and Reginald Annan}

Department of Biochemistry and Biotechnology, College of Science, Kwame Nkrumah University of Science and Technology, Ghana

\begin{abstract}
Diabetes mellitus is associated with hyperglycemia, which promotes oxidative stress through production of free radicals which may lead to diabetic complications such as cardiovascular diseases. However,it is proposed that dietary intakes of antioxidant micronutrients may help reduce oxidative stress in diabetes mellitus. The objective was to evaluate the protective effects of antioxidant micronutrients against CVD risk among type 2 diabetics.

Method: A systematic literature review including detailed search strategy was developed to search PubMed, PMC, PLOSONE, Google scholar and cochrane. Research articles were retrieved, screened and relevant articles were extracted. The exposure for review were zinc, vitamin E, and selenium, whereas measured outcomes were effects of antioxidant micronutrients on type 2 diabetes: reduced FBG and HbA1c, reduced lipidemia, improved antioxidant status, reduced oxidative stress.

Results: Among six cross-sectional studies; five studies indicated serum zinc were significantly reduced in type 2 diabetics than controls, whereas one study showed a higher serum selenium in type 2 diabetics than controls. Among five case-control studies used, two studies found serum zinc was lowered among type 2 diabetics than controls. Another study found serum vitamin $E$ was reduced in type 2 diabetics than controls $(p<0.05)$. The other studies showed supplementation of vitamin C, E improved significantly in levels of fasting blood glucose and glycated hemoglobin ( $p<0.05, p<0.001$ respectively). However, a case control study between type 2 diabetics with glycated haemoglobin $<7 \%$ and $\geq 7 \%$ showed no difference in serum zinc levels $(p=0.168)$. Out of five randomized controlled trials, two studies showed significant difference in fasting blood glucose, total antioxidant capacity, malondialdehyde in type 2 diabetics who received supplemented enriched tocotrienol canola oil at the end of study. However, type 2 diabetics supplemented with omega-3 plus vitamin $\mathrm{E}$, and zinc plus vitamin $\mathrm{C}$ showed no significant differences in cardiovascular risk markers compared to controls. Also, two studies which either supplemented type 2 diabetics with fermented diet containing supplemented chromium and zinc found no significant differences in glycated hemoglobin compared to placebo groups.
\end{abstract}

Conclusion: Antioxidant micronutrients could significantly reduce risk of cardiovascular diseases in type 2 diabetes and hence require further studies to ascertain its effects.

Keywords: Cardiovascular diseases (CVDs); Type 2 diabetes mellitus; Antioxidant micronutrients

Abbreviation: RCT: Randomized Controlled-Clinical Placebo Trials; HbA1c: Glycated Hemoglobin; FBG: Fasting Blood Glucose.

\section{Introduction}

In diabetes mellitus, there is persistent hyperglycemia and insulin resistance [1] which promotes development of endothelial cell injury and increased oxidative stress. Type 2 diabetes is likely to be affected by oxidative stress, secondary to persistent high blood glucose, lipid abnormalities due to generation of reactive oxygen species, formation of advanced glycosylated end products, dysfunctional glutathione metabolism and automatic oxidation of glucose [2]. This reduces their antioxidant capacity and it is proposed that dietary intakes of antioxidant micronutrients can play role in reducing oxidative stress [3]. Vitamin C is a significant hydrophilic antioxidant present in plasma of human. It has a protective role on immune function, anti-inflammatory and scavenges free radicals produced from oxidative process [4]. According to Song et al. [5] vitamin C also supply again depleted antioxidant reserve and thus prevent mediated damage from free radicals. Zinc is a micronutrient which influences glucose metabolism by promoting insulin sensitivity [6]. Zinc plays such role by involving in the synthesis, secretion and storage of insulin in pancreas [7]. Vitamin $\mathrm{E}$ is an important antioxidant which plays defence mechanism on lipid membrane; thereby prevents lipid peroxidation [2]. Vitamin $\mathrm{E}$ halts propagated chain reaction of lipid peroxyl radical formed in cells [8].
Although, several reviews and journal publications have been done on diabetes mellitus, there exist little data for antioxidant micronutrients in type 2 diabetes. According to Mahdizadeh et al. [9], clinical significance of antioxidant micronutrients in Type 2 diabetes mellitus is still controversial and requires further evaluation. A systematic search was performed to select studies published from April 2012 to October, 2016. The search evaluated the protective effects of antioxidant micronutrients status (vitamins and minerals from diet, serum and/or supplement) against CVD risk among type 2 diabetes mellitus patients.

\section{Method}

The search words used included "antioxidant micronutrients and risk of CVD, antioxidant micronutrients and type 2 diabetes mellitus, zinc, vitamin $\mathrm{E}$, and selenium, dietary intakes, CVD risk and type 2

*Corresponding author: Odeafo Asamoah-Boakye, Department of Biochemistry and Biotechnology, College of Science, Kwame Nkrumah University of Science and Technology, Ghana, Tel: +233276757691; E-mail: odeafoa@gmail.com

Received June 23, 2017; Accepted June 28, 2017; Published June 30, 2017 Citation: Asamoah-Boakye O, Apprey C, Annan R (2017) Effects of Antioxidant Micronutrients against CVD Risk in Type 2 Diabetes Mellitus: A Systematic Review. J Nutr Disorders Ther 7: 214. doi: 10.4172/2161- 0509.1000214

Copyright: (C) 2017 Asamoah-Boakye O, et al. This is an open-access article distributed under the terms of the Creative Commons Attribution License, which permits unrestricted use, distribution, and reproduction in any medium, provided the original author and source are credited. 
diabetes mellitus, serum vitamin $\mathrm{E}$ and type 2 diabetes mellitus, serum zinc and type 2 diabetes mellitus, serum selenium and type 2 diabetes mellitus, and Serum selenium and type 2 diabetes mellitus". The main outcome measured were effects of dietary supplementation of antioxidant micronutrients among type 2 diabetes mellitus patients, effects of antioxidant micronutrients status on type 2 diabetes through evaluation on: reduced fasting blood glucose and HbAlc, reduced lipidemia, improved antioxidant status, reduced oxidative stress. The electronic databases used in the search were PubMed, Cochrane, PMC, Google scholar and PLoS ONE. The search results identified these articles in the respective databases: PubMed (82), Cochrane (24), PMC (6545), Google Scholar (68380), and PLoS ONE (14542). After thorough evaluation of search articles, most of the articles that did not match inclusion criterion were discarded and other articles were eliminated because of irrelevant information and partial synthesis of data. After elimination of these articles, 16 articles containing full text of publications were included and evaluated. The included criteria were; studies on cross-sectional, case-control and randomized clinical controlled trial, human samples of all ages and gender, all age groups. The review excluded; articles in press, animal studies, case reports that did not meet inclusion criteria, review papers and type 1 and gestational diabetes articles

\section{Study Design}

Three study designs were identified out of which six were crosssectional study; five were case-control study which compared antioxidant micronutrients status of type 2 diabetes mellitus patients and their healthy controls. Also, five studies evaluated randomized clinical-controlled trials, where antioxidant micronutrients were incorporated in food as supplement to type 2 diabetes mellitus patients and control groups orally, and various outcomes were measured after the intervention.

\section{Antioxidant micronutrient included in study}

The main antioxidant micronutrients considered were vitamin E, zinc and selenium. However, other micronutrients such as copper, chromium, vitamin $\mathrm{C}$, manganese, magnesium, chromium and iron were assessed among type 2 diabetes mellitus patients and healthy non-diabetics to compare their status. Systematically, 91410 research articles were identified from all listed databases. A thorough reading of research articles eliminated 91305 based on titles, and/or abstracts and eligibility criteria. The remaining articles were 105 . A second thorough proofreading of 105 articles eliminated 89 articles based on exclusion criteria and duplicated papers. Finally 16 articles were accepted for the review. An illustration of search strategy is summarized below: Figure 1

Table 1 summarizes finding of randomized double-blind placebo controlled clinical trial studies retrieved from the review

Out of the five randomized controlled trials included, two studies showed significant difference in fasting blood glucose, total antioxidant capacity, fasting blood glucose, malondialdehyde in type 2 diabetics which received supplemented enriched tocotrienol canola oil, and at the end of study. However, a study which supplemented type 2 diabetics with omega-3 plus vitamin $\mathrm{E}$ and zinc plus vitamin $\mathrm{C}$ showed no significant differences in low density lipoprotein cholesterol, total cholesterol, glycated hemoglobin among type 2 diabetics (LDL-C: 113.0 $\pm 7.1 \mathrm{mg} / \mathrm{dL}$, TC: $197.0 \pm 7.1 \mathrm{mg} / \mathrm{dL}, \mathrm{HbAlc}: 9.2 \pm 0.3 \%)$ compared with controls (LDL-C: $100.0 \pm 7.9 \mathrm{mg} / \mathrm{dL}, \mathrm{p}=0.21$, TC: $180.0 \pm 6.6$ $\mathrm{mg} / \mathrm{dL}, \mathrm{p}=0.49$, HbA1c: $9.5 \pm 0.3 \%, \mathrm{p}=0.53$ ). Also, two studies which either supplement type 2 diabetics with fermented diet containing supplemented chromium and zinc or zinc capsules found no significant difference in glycated hemoglobin and total cholesterol compared to placebo groups. Another RCT study found that type 2 diabetic patients who had duration less than 7 years and received zinc plus vitamin $\mathrm{C}$ supplementation had significant decreased in $\mathrm{HbAlc}$ level before (HbA1c: $9.7 \pm 0.4 \%$, LDL-C: $143.4 \pm 10.3 \mathrm{mg} / \mathrm{dL}$ ) and after (HbA1c: $10.0 \pm 0.4 \%$, LDL-C: $120.7 \pm 10.3 \mathrm{mg} / \mathrm{dL}, \mathrm{p}=0.01, \mathrm{p}=0.003$ respectively) the study. Additionally, type 2 diabetic patients who had duration less than 7 years and received omega- 3 plus vitamin E supplementation had significant decreased in low density lipoprotein cholesterol before (HbAlc: $9.7 \pm 0.4 \%$, LDL-C: $127.8 \pm 11.2 \mathrm{mg} / \mathrm{dL}$ ) and after (HbAlc: $8.8 \pm 0.4 \%$, LDL-C:113.6 \pm $11.2 \mathrm{mg} / \mathrm{dL}, \mathrm{p}=0.001, \mathrm{p}=0.04$ respectively) the study.

\section{Table 2 summarizes finding of cross-sectional studies retrieved from the review}

Overall, six cross-sectional studies were included, and five studies indicated level of serum zinc were significantly reduced in type 2 diabetics compared with controls, whereas one study showed higher level of serum selenium in type 2 diabetics compared to controls. Within the five studies, two studies further reported serum zinc was lower in type 2 diabetics with complication $(89.6 \pm 4.2 \mu \mathrm{g} / \mathrm{dL}, 49.2 \pm 7.5$

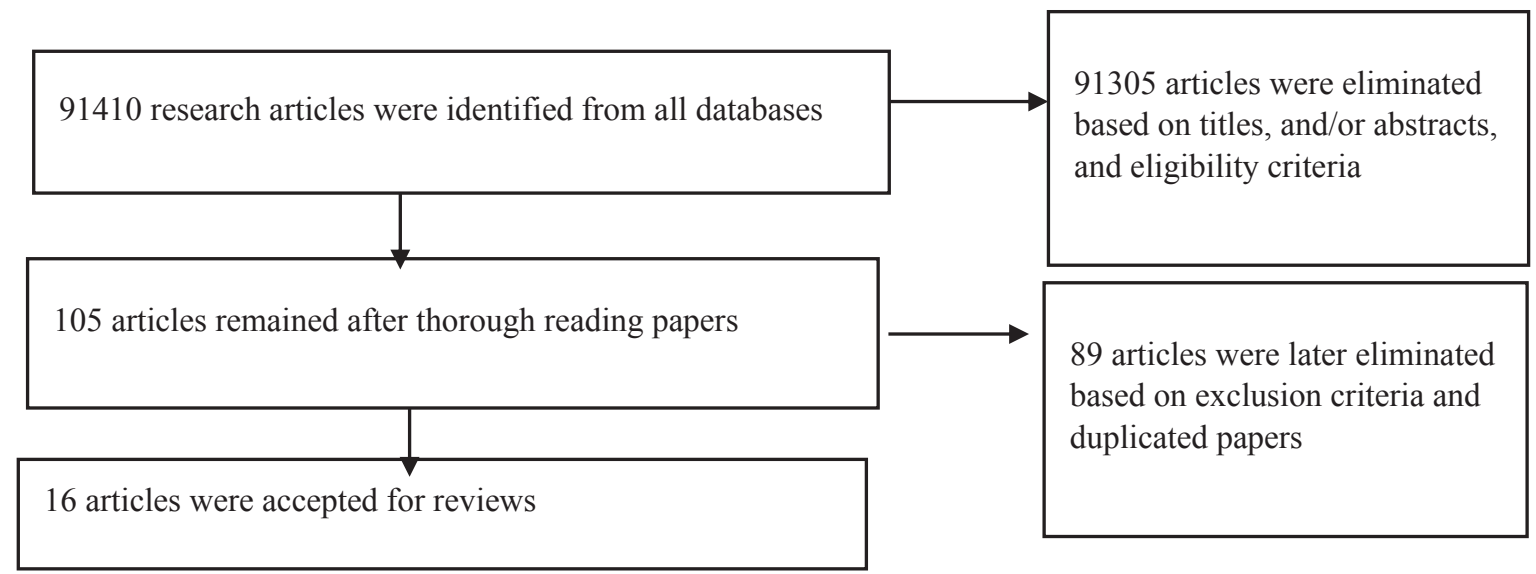

Figure 1: An illustration of search strategy. 
Citation: Asamoah-Boakye O, Apprey C, Annan R (2017) Effects of Antioxidant Micronutrients against CVD Risk in Type 2 Diabetes Mellitus: A Systematic Review. J Nutr Disorders Ther 7: 214. doi: 10.4172/2161- 0509.1000214

$\mu \mathrm{g} / \mathrm{dL})$ compared with type 2 diabetics without complication $(92.3 \pm$ $5.15 \mu \mathrm{g} / \mathrm{dL}, 64.7 \pm 8.4 \mu \mathrm{g} / \mathrm{dL})(\mathrm{p}<0.001, \mathrm{p}=0.024$ respectively).

\section{Table 3 summarizes finding of case-control studies retrieved from the review}

Among the five case-control studies used, two studies found serum zinc was lowered among type 2 diabetics than controls. One of the two studies found strong, inverse significant correlation between serum zinc and glycated hemoglobin in type 2 diabetics $(r=-0.56$, $\mathrm{p}<0.001)$. Another study found serum vitamin $\mathrm{E}$ was significantly reduced in type 2 diabetics compared with controls. The other study showed supplementation of vitamin $\mathrm{C}, \mathrm{E}$ and combined vitamin $\mathrm{C}$ and $\mathrm{E}$ improved significantly in levels of plasma fasting blood glucose and glycated hemoglobin after 3 months ( $<<0.05, p<0.001$ respectively). However, a case-control study between type 2 diabetics with glycated hemoglobin $<7 \%(0.15 \pm 0.02 \mathrm{mg} / \mathrm{dL})$ and $\geq 7 \%(0.13 \pm 0.02 \mathrm{mg} / \mathrm{dL})$ showed no significant difference in serum zinc levels $(\mathrm{p}=0.168)$.

\begin{tabular}{|c|c|c|c|c|c|c|c|c|}
\hline Lead Author and Country & Year & Study population & Micronutrient & Main findin & & Type 2 diabetic & & \\
\hline \multirow{6}{*}{$\begin{array}{c}\text { 1.Mahmoodi et al., 2014, } \\
\text { Iran }\end{array}$} & \multirow{6}{*}{2014} & \multirow{6}{*}{75} & \multirow{6}{*}{$\begin{array}{c}\text { Vitamin C, Vitamin } \\
\text { E, zinc }\end{array}$} & \multicolumn{2}{|c|}{ Outcome } & Intervention & Control & $P$ value \\
\hline & & & & & & 50 & 25 & \\
\hline & & & & \multicolumn{2}{|l|}{ LDL-C } & $113.0 \pm 7.1$ & $100.0 \pm 7.9$ & 0 \\
\hline & & & & \multicolumn{2}{|l|}{$\mathrm{HbA1c}$} & $9.2 \pm 0.3$ & $9.5 \pm 0.3$ & 1 \\
\hline & & & & \multicolumn{2}{|l|}{ TC } & $197.0 \pm 7.1$ & $180.0 \pm 6.6$ & 1 \\
\hline & & & & & & 36 & 12 & \\
\hline \multirow{4}{*}{$\begin{array}{l}\text { 2.Samman et al., 2013, } \\
\text { Australia }\end{array}$} & \multirow{4}{*}{2013} & \multirow{4}{*}{48} & \multirow{4}{*}{ Zinc } & HbA1c(base & ine) & $6.6 \pm 0.3$ & $6.6 \pm 0.3$ & $>0.05$ \\
\hline & & & & $\mathrm{HbA} 1 \mathrm{c}(\mathrm{aft}$ & & \multirow{2}{*}{$6.8 \pm 0.3$} & $6.6 \pm 0.3$ & \\
\hline & & & & \multicolumn{2}{|c|}{ TC(baseline) } & & $4.5 \pm 0.3$ & $>0.05$ \\
\hline & & & & \multicolumn{2}{|l|}{ TC(after) } & $4.0 \pm 0.3$ & $4.6 \pm 0.3$ & \\
\hline & & & & & & 23 & 22 & \\
\hline & & & & TAC (Baseli & ne) & $4.2 \pm 0.5$ & Not reported & 0 \\
\hline & & & & TAC (afte & & $3.4 \pm 0.8$ & & \\
\hline 3. Vafa et al 2015 Iran & 2015 & 50 & Vitamin $\mathrm{F}$ & TAC) & & $4.2 \pm 0.5$ & $4.4 \pm 0.4$ & 0 \\
\hline & & 50 & vitamilit ᄃ & FBS (media & n ) & $121.0(98-140)$ & $141.0(114.5-210.0)$ & 0 \\
\hline & & & & MDA(baseli & ne) & $3.2 \pm 1.4$ & Not reported & 0 \\
\hline & & & & MDA(afte & & $2.1 \pm 1.1$ & & \\
\hline & & & & & & 19 & 17 & \\
\hline & & & & $\mathrm{HbA} 1 \mathrm{c}(\%$ cha & nge) & $0.09 \pm 0.4$ & $0.01 \pm 0.6$ & 1 \\
\hline 4. Lee et al., 2016, & 2016 & 36 & 7inc Chromiun & TC (treatment & effect) & $-6.5(-43$ to 64$)$ & $5.5(-106$ to 108$)$ & 1 \\
\hline Germany & $\angle 010$ & 20 & 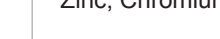 & LDL-C(treatmen & t effect) & $-5.0(-47$ to 71$)$ & $3.0(-92$ to 95$)$ & 1 \\
\hline & & & & HDL-C(treatmen & t effect) & $1.0(-9.0$ to 31$)$ & $0.5(-9.0$ to 8.0$)$ & 1 \\
\hline & & & & & & 70 & 24 & \\
\hline 5 Idung et al 2012 India & 2012 & 94 & Vitamin F & BMI & & $29.7 \pm 8.6$ & $31.3 \pm 2.5$ & 0 \\
\hline 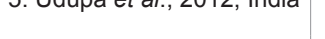 & 2012 & 94 & vidamiti ᄃ & $\mathrm{TC}(\mathrm{mg} / \mathrm{dL}$ & & $186.7 \pm 19.3$ & $211.1 \pm 24.4$ & 0 \\
\hline & & & & $\mathrm{FBS}(\mathrm{mg} / \mathrm{d}$ & & $144.0 \pm 21.9$ & $146.9 \pm 23.9$ & 0 \\
\hline $\begin{array}{l}\text { Data is presented in mean } \pm S \\
\text { Density Lipoprotein Cholester }\end{array}$ & $\begin{array}{l}\mathrm{D}, \mathrm{med} \\
\mathrm{Ol}, \mathrm{HDL}\end{array}$ & $\begin{array}{l}\text { lian (range) and perce } \\
- \text {-C: High Density Lipo }\end{array}$ & $\begin{array}{l}\text { entage change in out } \\
\text { oprotein Cholesterol, }\end{array}$ & $\begin{array}{l}\text { tcome measure level. } \\
\text { TAC: Total Antioxidan }\end{array}$ & $\begin{array}{l}\text { HbA1c: } \\
\text { t Capaci }\end{array}$ & $\begin{array}{l}\text { fated hemoglobin } \\
\text { MDA: Malondiald }\end{array}$ & $\begin{array}{l}\text { TC: Total Cholesterol, LD } \\
\text { hyde }\end{array}$ & -C: Low \\
\hline Tab & $1: S$ & nmary description of $r$ & results obtained from & n Randomized, double & -blind $p$ & o-controlled tri & RCT) studies. & \\
\hline Lead Author and Country & Year & Study population & Micronutrients & Outcome & & & & \\
\hline & & & & & T2DM v & ith complication & T2DM without complication & $P$ value \\
\hline 1.Devi et al., (2016), India & 2016 & 80 & Zinc and copper & & & 40 & 40 & \\
\hline & & & & Serum zinc $(\mu \mathrm{g} / \mathrm{dL})$ & & $9.6 \pm 4.2$ & $92.3 \pm 5.2$ & 0.001 \\
\hline 2.Tabar, M.B. (2012), Iran & 2012 & 80 & Selenium & & Typ & 2 diabetics & Control & \\
\hline & & & & $\begin{array}{l}\text { Serum selenium(ng/ } \\
\mathrm{mL})\end{array}$ & & 33 & 47 & \\
\hline & & & & & & $7.9 \pm 5.8$ & $87.0 \pm 5.5$ & $<0.05$ \\
\hline & & & & & Type 2 & diabetics (109) & Control (100) & \\
\hline et al 2015 & & & Copper, zinc, & & & $3.4 \pm 4.4$ & $112.5 \pm 9.2$ & \\
\hline Nigeria & 2015 & 209 & $\begin{array}{l}\text { magnesium, } \\
\text { chromium }\end{array}$ & Serum zinc $(\mu \mathrm{g} / \mathrm{dL})$ & Type & diabetics (53) & Control (50) & 0 \\
\hline 4. Olaniyan et al., 2012, & 2012 & 103 & Zinc conper & Serum zinc(umol/L) & & $1.9 \pm 2.9$ & $14.6 \pm 2.5$ & 0,001 \\
\hline Nigeria & 2012 & 103 & Zinc, copper & serum zinc( $\mu \mathrm{mol} / \mathrm{L})$ & Type & diabetics $(55)$ & Control (55) & 0.001 \\
\hline 5. Farid and Abulfaraj, 2013, & 2013 & 110 & $\begin{array}{l}\text { Zinc, magnesium, } \\
\text { chromium, copper }\end{array}$ & Serum zinc $(\mu \mathrm{g} / \mathrm{dL})$ & & $3 \pm 24.3$ & $130.2 \pm 32.0$ & $<0.05$ \\
\hline 6. Saharia & 2012 & 100 & 7 inc & Serum zinc $(\mu \mathrm{g} / \mathrm{dL})$ & & $.8 \pm 13.4$ & $109.7 \pm 9.7$ & 0.001 \\
\hline & 2013 & 100 & $\angle \mathrm{IITC}$ & Correlation (r) & & -0.804 & Not reported & 0.001 \\
\hline
\end{tabular}

Data is presented in means \pm standard deviation

Table 2: Summary description of results obtained from Cross-sectional studies. 


\begin{tabular}{|c|c|c|c|c|c|c|c|}
\hline Lead Author and Country & Year & Study population & Micronutrients & Outcome measures & Type 2 diabetics & & \\
\hline \multirow{5}{*}{ 1.Pujar et al., 2014, India } & \multirow{5}{*}{2014} & \multirow{5}{*}{100} & \multirow{5}{*}{$\begin{array}{l}\text { Zinc, copper and } \\
\text { magnesium }\end{array}$} & & Case group (50) & Control (50) & $P$ value \\
\hline & & & & & $67.5 \pm 13.8$ & & \\
\hline & & & & Serum zinc $(\mu \mathrm{g} / \mathrm{dL})$ & -0.56 & $89.6 \pm 27.7$ & 0.001 \\
\hline & & & & Correlation ( $r$ ) & & - & 0.001 \\
\hline & & & & & $\mathrm{N}=40$ & & \\
\hline 2.Goud et al., 2016, India & 2016 & 60 & Vitamin $\mathrm{E}$, iron & Serum vitamin $E(\mu \mathrm{g} / \mathrm{dL})$ & $0.6 \pm 0.4$ & $1.4 \pm 0.2$ & 0.001 \\
\hline \multirow{5}{*}{ 3. Ramaswamy et al., 2016, India } & \multirow{5}{*}{2016} & \multirow{5}{*}{73} & \multirow{5}{*}{$\begin{array}{l}\text { Zinc, } \\
\text { magnesium, } \\
\text { chromium, } \\
\text { calcium }\end{array}$} & & $\mathrm{HbA} 1 \mathrm{c}<7 \%(34)$ & $\mathrm{HbA} 1 \mathrm{c} \geq 7 \%$ & \\
\hline & & & & Serum zinc(mg/dL) & $0.15 \pm 0.02$ & -39 & 0.168 \\
\hline & & & & & & $0.13 \pm 0.02$ & \\
\hline & & & & & 60 & & \\
\hline & & & & & & 60 & \\
\hline \multirow{2}{*}{ 4. Mahdizadeh et al., 2014, Iran } & \multirow{2}{*}{2014} & \multirow{2}{*}{120} & \multirow{2}{*}{ Copper, Zinc } & \multirow{2}{*}{ Serum zinc $(\mu \mathrm{g} / \mathrm{dL})$} & $95.9 \pm 15.7$ & $113.9 \pm 14.0$ & \multirow{2}{*}{0.001} \\
\hline & & & & & $N=130$ & $\mathrm{~N}=40$ & \\
\hline 5. Rafighi et al., 2013, Iran & 2013 & 170 & Vitamin $\mathrm{C}$ and $\mathrm{E}$ & $\begin{array}{c}\text { Significant difference in plasma FBG } \\
\text { and } \mathrm{HbA} 1 \mathrm{c} \text { after receiving vitamin } \mathrm{C}, \mathrm{E} \\
\text { and combined vitamin } \mathrm{C} \& \mathrm{E}\end{array}$ & Not reported & Not reported & $<0.05$ \\
\hline
\end{tabular}

Table 3: Summary description of results obtained from Case-control studies.

\section{Discussion}

The systematic review conducted included six cross-sectional studies, 5 randomized double-blind controlled- clinical trials, and 5 case control studies. The results obtained from 6 cross-sectional studies indicated that serum antioxidants micronutrients such as zinc and selenium were significantly lowered in type 2 diabetes (selenium: 0.47 $\pm 0.03 \mu \mathrm{mol} / \mathrm{L}$, zinc: $18.15 \pm 0.33 \mu \mathrm{mol} / \mathrm{L}, 53.41 \pm 4.35 \mu \mathrm{g} / \mathrm{dL}$ ) compared to healthy controls (selenium: $1.02 \pm 0.01$, zinc: $21.86 \pm 0.06 \mu \mathrm{mol} / \mathrm{L}$, $112.46 \pm 9.23 \mu \mathrm{g} / \mathrm{dL}, \mathrm{p}$ values $<0.002)$. Hyperglycemia increases risk of oxidative damage on endothelial cells, leading to atherosclerosis in type 2 diabetes [10]. It was noted that serum zinc level had inverse correlation with glycated hemoglobin levels of type 2 diabetic patients [11-12]. This implies that an increase in zinc concentration in blood will cause decrease in glycated hemoglobin in type 2 diabetics. This also explains the role of zinc on insulin secretion, sensitivity and storage can contribute in reducing blood glucose levels in type 2 diabetics. Subsequently, positive effects of zinc on blood glucose can contribute to reduce risk of oxidative stress. However, in the study by Olaniyan et al. [13], there was no correlation between serum zinc levels and fasting blood glucose in type 2 diabetic patients. Also, it was observed that type 2 diabetic patients with $\mathrm{HbAlc}$ greater than $8 \%$ had strong correlation with regard to altered serum zinc compared to those with $\mathrm{HbAlc}$ less than $8 \%$ [11]. This means that altered zinc levels can enhance increase in blood glucose. Consequently, hyperglycemia would prevail due to altered zinc concentration and can cause metabolic disturbance such as dyslipidemia and oxidative stress which can lead to cardiovascular risk in type 2 diabetes

According to Farid and Abulfaraj [11], reduced serum zinc levels in type 2 diabetic patients may contribute to increase excretion of antioxidant micronutrient in urine as a result to hyperglycemia in uncontrolled diabetes. Also, it could be that, significant reduction of antioxidant micronutrients is indicative of metabolic response to oxidative stress occurring in patients with type 2 diabetes mellitus [3]. According to Myke-Mbata et al. [14], reduced concentration of antioxidant micronutrient in type 2 diabetic patients may contribute to imbalance of antioxidant and oxidative stress in type 2 diabetes mellitus.

Furthermore, results obtained from 5 case control studies showed serum zinc and vitamin $\mathrm{E}$ were significantly decreased in type 2 diabetic patients (zinc: $67.50 \mu \mathrm{g} / \mathrm{dL}$, vitamin E: $0.595 \pm 0.393 \mathrm{mg} / \mathrm{dL}$ ) compared to healthy controls (zinc: $89.61 \pm 61 \mu \mathrm{g} / \mathrm{dL}$, vitamin E: $1.400 \pm 0.241 \mathrm{mg} /$ dL) $[2,7,9]$. A significant decrease in vitamin $\mathrm{E}$ and zinc concentrations in type 2 diabetes explains possible decrease in antioxidant status which would alternatively increase risk of oxidative stress from production of free radicals. In addition, a case control study by Rafighi et al. [1] showed supplementation of vitamin $\mathrm{C}$ and vitamin $\mathrm{E}$ for three months had significant reduction in fasting blood glucose and $\mathrm{HbAlc}$ levels of type 2 diabetic patients compared to placebo group. This implies that given dietary vitamin $\mathrm{C}$ or vitamin $\mathrm{E}$ supplements to type 2 diabetics can possibly reduce tissue insensitivity to insulin and stress from oxidative free radicals and further delay cardiovascular events.

The results revealed from 5 randomized controlled-clinical placebo trials (RCT) showed some beneficial effects when type 2 diabetic patients were supplemented with antioxidant micronutrients such as vitamin C and vitamin E. According to Vafa et al. [15], $200 \mathrm{mg} /$ day fortification of tocotrienol in canola oil, given to type 2 diabetic patients for 8 weeks, reduced fasting blood glucose by $15.4 \%$ compared to type 2 diabetic patients who were given pure canola oil. Similar result was observed by Udupa et al. [16] who found significant decreased in fasting blood glucose in type 2 diabetic patients receiving vitamin $\mathrm{E}$ supplementation as well as reduced total cholesterol at the end of study. The result by Vafa et al. [15] showed significant improvement of total antioxidant capacity, fasting blood glucose and reduced oxidative status of type 2 diabetic patients who received tocotrienol enriched canola oil at the end of study. This means vitamin $\mathrm{E}$ and vitamin $\mathrm{C}$ can inhibit or delay oxidative damage caused by free radicals by exerting antioxidant activities on biomolecules. An improvement in total antioxidant status implies supplementation or dietary intake of vitamin $\mathrm{E}$ can counteract oxidative stress in type 2 diabetics by mopping free radicals from oxidative damage.

In a study by Mahmoodi et al. [17], it was found that type 2 diabetic patients who had duration less than 7 years and received zinc plus vitamin $\mathrm{C}$ supplementation had significant decreased in $\mathrm{HbA1c}$ level before (HbA1c: $9.7 \pm 0.4 \%$, LDL-C: $143.4 \pm 10.3 \mathrm{mg} / \mathrm{dL}$ ) and after (HbA1c: $10.0 \pm 0.4 \%$, LDL-C: $120.7 \pm 10.3 \mathrm{mg} / \mathrm{dL}, \mathrm{p}=0.01, \mathrm{p}=0.003$ respectively) the study. Additionally, type 2 diabetic patients who had duration less than 7 years and received omega-3 plus vitamin $\mathrm{E}$ 
supplementation had significant decreased in low density lipoprotein cholesterol before (HbA1c: $9.7 \pm 0.4 \%$, LDL-C:127.8 $\pm 11.2 \mathrm{mg} / \mathrm{dL}$ ) and after (HbA1c: $8.8 \pm 0.4 \%$, LDL-C: $113.6 \pm 11.2 \mathrm{mg} / \mathrm{dL}, \mathrm{p}=0.001$, $\mathrm{p}=0.04$ respectively) the study. It could be inferred from this study that oxidative stress and atherosclerosis may be long progressive complication which can weaken antioxidant defence of type 2 diabetic patients. Apparently, supplementation of antioxidant micronutrients did significantly improve cardiovascular risk markers of the type 2 diabetics which might counteract against possible oxidative stress in these patients.

On a whole, results analyzed in the cross-sectional and case-control studies did not provide enough evidence on association between serum antioxidant micronutrients and CVD risk in type 2 diabetes mellitus, however, antioxidant micronutrients were significantly reduced among type 2 diabetics

Notwithstanding, some RCT showed no beneficial effects of antioxidant micronutrients on type 2 diabetic patients and placebo groups after intervention. A study by Samman et al. [18] showed no beneficial effects of zinc supplementation on glycemia and lipidemia in type 2 diabetic patients after 12 weeks' intervention. The same result was observed by Lee et al. [19] after $15 \mathrm{mg}$ supplementation of zinc.

From the results obtained in systematic review, it is clear that "some studies on antioxidant micronutrients of type 2 diabetes mellitus had shown some beneficial effects of antioxidant micronutrients in reducing cardiovascular risk parameters. However, results had been conflicting from other studies which showed no significant effects of antioxidant micronutrients. Hence, this becomes inconclusive on association effects of antioxidant micronutrients in reducing risk of developing cardiovascular diseases", and require further research to evaluate such effects of antioxidant micronutrients on type 2 diabetes mellitus. Also, fewer studies on effects of antioxidant micronutrients of type 2 diabetes mellitus had been done in sub-saharan Africa, with only two studies in Nigeria.

\section{Conclusion}

The results support growing evidences that antioxidant micronutrients could significantly protects type 2 diabetics against risk of cardiovascular diseases. There is need for health promotion on increasing intake of antioxidant micronutrients among type 2 diabetics to reduce risk of cardiovascular diseases.

Results analyzed in RCT studies showed supplementation of vitamin $\mathrm{E}$ is associated with reducing cardiovascular events in type 2 diabetes mellitus. However, supplementation of zinc showed no association in reducing cardiovascular diseases in type 2 diabetes mellitus.

\section{Limitation}

Majority of studies did not include dietary intakes of antioxidant micronutrients to better conclude if type 2 diabetic patients had adequate antioxidant micronutrients intake, to better correlate with their serum levels and blood glucose. Also, most studies had less sample size numbers to actually represent population of type 2 diabetic patients so as to better elicit effects of antioxidant micronutrients status of type 2 diabetes against risk of CVDs.

\section{Acknowledgement}

The review paper acknowledges the staff at University's electronic resource centre and the staff at research commons for their support in retrieving review articles.

\section{References}

1. Rafighi Z, Shiva A, Arab S, Yusuf RM (2013) Association of Dietary Vitamin C and $E$ intake and Antioxidant enzymes in Type 2 Diabetes Mellitus Patients. Glob J Health Sci 5: 183-187

2. Goud VGK, Patil S, Rahman MA (2016) A study of Antioxidant and Iron nutritional status in Type 2 Diabetes Mellitus with and without Coronary Heart disease. Int J Biomed Res 7: 495-498.

3. Tabar MB (2012) Determination of Serum Selenium in Patients with Type II Diabetes Mellitus. Middle-East J Sci Res 12: 433-435.

4. Badawi A, Garcia-Bailo B, Arora P, Al Thani MK, et al. (2013) The Utility of Vitamins in the Prevention of Type 2 Diabetes Mellitus and its Complications: A Public Health Perspective. Intech Open Science Chapter 1.

5. Song Y, Cook NR, Albert CM, Denburgh MV, Manson JE (2009) Effects of Vitamin $\mathrm{C}$ and $\mathrm{E}$ and Beta-carotene on the risk of Type 2 diabetes in Women at high risk of Cardiovascular disease: a randomized controlled trial. Am J Clin Nutr 90: 429-437.

6. Devi TR, Hijam D, Dubey A, Debnath S, Oinam P, et al. (2016) Study of Serum Zinc and Copper in Type 2 Diabetes Mellitus. Int J Contemporary Med Res 3: 1036.

7. Pujar S, Pujar LL, Ganiger A, Hiremath K, Mannangi N et al. (2014) Correlation of Serum Zinc, Magnesium and Copper with $\mathrm{HbA} 1 \mathrm{c}$ in Type 2 Diabetes patients among Bagalkot population: A case control study. Medical Innovatica 3: 4-8.

8. Goldenstein H, Levy NS, Lipener YT, Levy AP (2013) Patient Selection in Vitamin E Treatment in Diabetes Mellitus. Expert Rev Cardiovasc Ther 11 319-326.

9. Mahdizadeh R, Shirali S, Ebadi P (2014) Investigation of Imbalances of Trace elements in Patients with Type 2 Diabetes Mellitus. Journal of Academic and Applied Studies 4: 11-21

10. Doddigarla Z, Parwez I, Ahmad J (2015) Correlation of Serum Chromium, Zinc Magnesium and SOD levels with HbA1c in Type 2 Diabetes: A cross-sectional analysis. Diabetes Metab Syndr 10: S126-9.

11. Farid SM, Abulfaraj TG (2013) Trace Mmineral status related to levels of glycated hemoglobin of Type 2 Diabetic subjects in Jeddah, Saudi Arabia. Med J Islamic World Aca Sci 21: 47-56.

12. Saharia GK, Goswani RW (2013) Evaluation of Serum Zinc status and Glycated Hemoglobin of Type 2 Diabetes Mellitus Patients in a Tertiary Care Hospital of Assam. J Lab Physicians 5: 30-33.

13. Olaniyan OO, Awonuga MAM, Ajetumobi AF, Adeleke IA, Fagbolade OJ, et al. (2012) Serum Copper and Zinc levels in Nigerian Type 2 Diabetic patients. African J Diabetes Med 20: 36

14. Myke-Mbata BK, Meludu SC, Obochi GO, Nnodim JK (2015) Variations in some trace elements in various degrees of Diabetes Mellitus. Ai Ameen Journal of Medical Science 8: 271-275.

15. Vafa M, Haghighat N, Moslehi N, Eghtesadi S, Heydari I (2015) Effects of Tocotrienol enriched canola oil on glycemic control and oxidative status in Patients with Type 2 Diabetes Mellitus: A randomized, double-blind, placebocontrolled trials. J Res Med Sci 20: 540-547.

16. Udupa AS, Nahar PS, Shah SH, Kshirsagar MJ, Ghongane BB (2012) Study of Comparative effects of Antioxidants on Insulin Sensitivity in Type 2 Diabetes Mellitus. J Clin Diagn Res 6: 1469-1473.

17. Mahmoodi MR, Kimiagar M, Mehrabi Y (2014) The effects of Omega-3 plus Vitamin E and Zinc plus Vitamin C Supplementation on Cardiovascular risk markers in Postmenopausal women with Type 2 Diabetes. Ther Adv Endocrinol Metab 5: 67-76.

18. Samman S, Foster M, Petocz P, Caterson ID (2013) Effects of Zinc and alpha linoleic acid Supplementation on Glycemia and Lipidemia in women with Type 2 Diabetes: A randomized, double-blind, placebo-controlled trial. J Diabetes Res Clin Metab 2: 3

19. Lee Y, Wolf P, Hauner H, Skurk T (2016) Effects of a fermented Dietary supplement containing Chromium and Zinc on Metabolic control in Patient with Type 2 Diabetes. A randomized, placebo-controlled, double-blind cross-over study. Food Nutr Res 60: 30298. 